\title{
Leishmaniasis: still a diagnostic challenge?
}

\begin{abstract}
American cutaneous leishmaniasis (ACL) should be differentiated from traumatic ulcers, venous ulcers, tropical ulcer, lower limb ulcers due to sickle cell anemia, pyodermatitis, paracoccidioidomycosis, syphilis, cutaneous neoplasms, among others. ${ }^{1}$ Histopathology may be suggestive, but it is rarely specific enough to make the diagnosis without identification of the amastigote forms of the parasite. ${ }^{2}$ Among the non-specific alterations to the histopathological examination, pseudoepitheliomatous hyperplasia (PEH) presents as a challenge, especially in the differential diagnosis with squamous cell carcinoma (SCC).
\end{abstract}

Keywords: leishmaniasis, pseudoepitheliomatous hyperplasia, carcinoma
Volume 5 Issue 2 - 2021

\author{
Villa RT, Rios RT,Tranquillini G, Zorzetto IFH, \\ Silva TA \\ Federal University of Maranhão, Brazil
}

Correspondence: Ricardo Tadeu Villa, Professor UFMA,

Federal University of Maranhão, Brazil,

Email ricardovilladermato@hotmail.com

Received: February 25, 2021 | Published: April 01, 2021

\section{Case report}

A previously healthy 30-year-old female housewife, from the municipality of Barra do Corda, in the central-southern region of the state of Maranhão, Brazil, was referred to the Dermatology department of the President Dutra University Hospital with an ulcer in the face for three months.

In her family history, she highlights the fact that her husband was under treatment for cutaneous leishmaniasis. In addition, attention was drawn to the fact that this region of the state is endemic to ACL. In the personal background, she has received multiple topical and systemic treatments for her lesion, including antibiotics and corticosteroids, with progressive enlargement and infiltration of the lesion.

At the examination, she presented a $5 \mathrm{~cm}$ diameter ulcer covered by dry crust, located on her right malar region, inside an infiltrated, erythematous plaque, and surrounded by small pustules (Figure 1). No other lesions or abnormalities on physical examination.

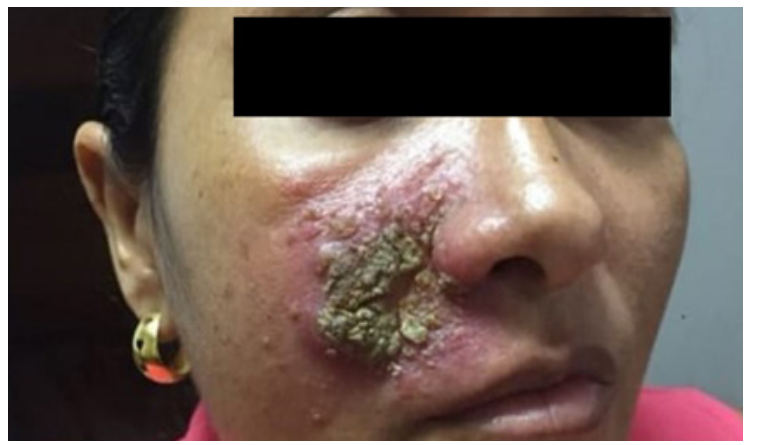

Figure I Ulcer covered by dry crust inside a more extensive area of oedema and erythema and some pustules.

The patient reported that the lesion was initially very small and comparable to those caused by insect bites, with which she was used to and, initially, there was no major concern. As the ulcer increased, she sought medical help in her area, but since the presentation of the lesion left many doubts about the diagnosis, she was referred to the university hospital for further investigation.

At the hospital, several blood tests were requested and a biopsy was taken. Since she had a solid epidemiological background and a compatible clinical presentation, treatment for ACL was instituted with meglumine antimoniate, $20 \mathrm{mg}$ per kilogram per day, for 30 days.
By the end of the treatment, her lesion was no longer visible (Figure 2).

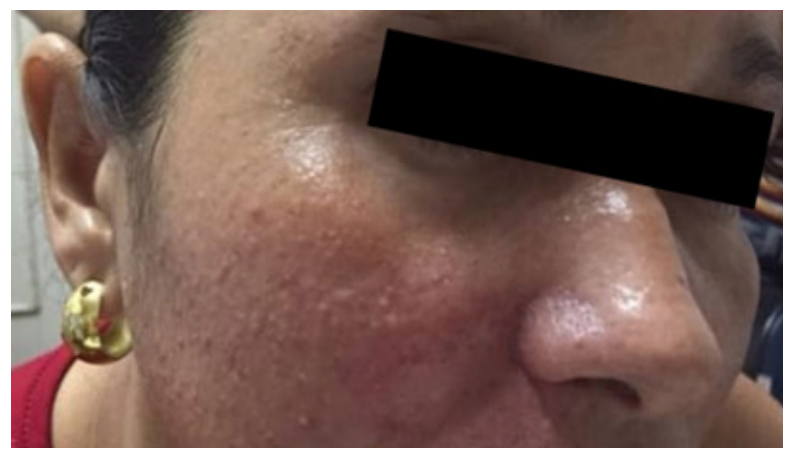

Figure 2 Same region after 30 days of treatment. It is well worth noting that no scar is visible.

About forty days after biopsy was taken (and, therefore, after her treatment had ended), her histopathological examination revealed pseudoepitheliomatous hyperplasia and a diagnosis of squamous cell carcinoma was suggested by the pathologist. Once a complete clinical response to meglumine antimoniate was obtained, a more accurate approach to the biopsy specimen led to the finding of amastigotes forms of Leishmania sp (Figure 3).

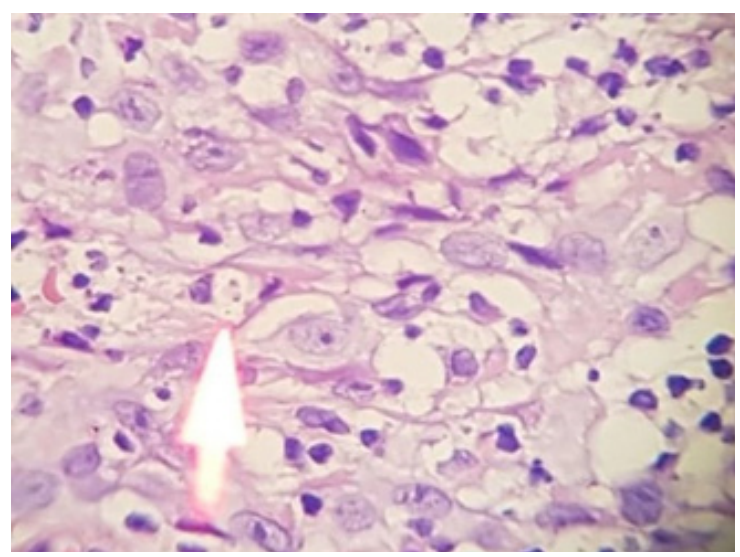

Figure 3 Amastigote form inside macrophage.

As in the common routine for leishmaniasis in Brazil, follow up at one, three and six months didn't exhibited any sign of the previous disease. 


\section{Discussion}

ACL is an infectious disease, not contagious, caused by different species of protozoa of the genus Leishmania, transmitted by sting of sandflies and affecting skin and mucous membranes. In Brazil, it is a disease with a diversity of agents, reservoirs and vectors that presents different transmission patterns and a limited knowledge about some aspects, which makes it difficult to control. ${ }^{3}$

Leishmania is a protozoan belonging to the family Trypanosomatidae, an obligate intracellular parasite of cells of the mononuclear phagocytic system, with two main forms: a flagellate or promastigote, found in the digestive tract of the insect vector, and another aflagellate or amastigote observed in the tissues of vertebrate hosts. $^{4}$

The typical clinical manifestation of ACL corresponds to a single ulcer, rounded, painless, measuring up to a few centimeters. Usually, has an infiltrated and hardened base with raised and well delimited erythematous borders and granular and reddish background. The most affected sites are exposed areas of the body, more accessible to the bites of the vectors, for example, the face. ${ }^{5}$

Although ACL ordinarily presents as this typical ulcer discribed above, its diagnosis is not always simple, because there are several other possible clinical presentations that make this confirmation difficult. Some described varieties are sporotrichoid, psoriasiform, lupic, erisipeloid, mycetomatous, periungueal, eczematous, zosteriform, annular, palmoplantar, cicatricial, vegetant, impetigoid and squamous cell carcinoma-like. ${ }^{6}$

As well as the clinical presentation, the findings of microscopic examination display great variability, which are related to factors such as the time of disease progression and the macroscopic aspect of the lesion, and the sampling and the immunological status of the patient. ${ }^{7}$ Nonetheless, histopathology of ACL commonly reveals a hyperplasia of epidermis and ulceration, in addition to inflammation with a diffuse dermal infiltrate, mainly of macrophages, where predominantly amastigote forms are found. ${ }^{8}$ In fact, since a nonspecific set of characteristics is the rule, only the visualization of the amastigote forms confirms the diagnosis. ${ }^{1}$

Recently, a study that analyzed 378 biopsies of patients infected with $L$. brasiliensis, showed that most of the cases under study exhibited varying degrees of epidermal thickening at the borders, constituting PEH, at various levels. They also verified that the amastigote forms were scarce in the samples and that the amount of these was inversely proportional to the evolution time of the lesions. ${ }^{9}$ This is in accordance with the case portrayed here, since the first diagnosis was of SCC, taking into account the scarcity of amastigote forms, they were not seen in a less judicious examination of the biopsy material.

Although PEH had been exhaustively studied and easily identifiable as proliferation of epidermis with markedly elongated and anastomotic projections, besides a strong infiltration of inflammatory cells, and a varying degree of hyperkeratosis and papillomatosis, ${ }^{10}$ the function of PEH is not yet clear. Presumably, it is a physiological response to various types of skin damage and a defense mechanism for elimination of foreign bodies. ${ }^{11}$ As a corollary, wrong approaches could bring discomfort and sequelae for patients or may retard resolution. In this sense, the differential diagnosis, mostly with malignant conditions, as SCC, should always remain on the radar of the clinician and the pathologist and this is the explanation for the initial misdiagnosis in this case report.
It is important to highlight that, sometimes, an additional biopsy should be performed to identify the underlying disease process. ${ }^{12}$ In this particular aspect, some bizarre causes of PEH were mentioned before in literature, as the patient who doodled an amateur tattoo in his arm with inappropriate ink, that he took from his son's pencil case. ${ }^{13}$ On the other side, it shoud not be forgotten, that, although most SCC cases are readily diagnosable, some challenges are occasionally encountered, as SCC could present a wide variety of histopathologic features and and small biopsy specimens which reveal only part of the lesion. ${ }^{14,15}$

At last, another important aspect is the causal association between leishmaniasis and malignancy suggested both in animals and in humans. In these cases, infection may play a significant role, directly or indirectly, in the pathogenesis and prognosis, through numerous pathophysiological cascades, paving the way for mutations and the development of skin cancer. ${ }^{16,17}$

\section{Conclusion}

These brief case report illustrates some aspects of the importance of thorough clinical and histological investigation and the pursuit for differencial diagnosis, particularly in leishmaniasis, always keeping in mind the famous phrase of canadian physician William Osler: "Medicine is a science of uncertainty and an art of probability". Of particular interest, the epidemiological background and the careful review of the biopsy material saved the patient from a mutilating surgery with severe consequences for self-image.

\section{Funding}

None.

\section{Conflicts of interest}

The authors declare no conflict of interest.

\section{Acknowledgments}

None.

\section{References}

1. Gontijo B, Carvalho MLR. American cutaneous leishmaniasis. Revista da Sociedade Brasileira de Medicina Tropical. 2003;36(1):71-80.

2. Cardoso CPL, Dadalti P, Gutierrez MCG, et al. Leishmaniose: métodos diagnósticos. Folha Médica, Rio de Janeiro. 1998;117(2):131-134.

3. Araujo LM, Maia DCC, Agonio B, et al. Leishmaniose tegumentar americana-apresentação atípica diagnosticada com técnica de biologia molecular. Revista da Sociedade Portuguesa de Dermatologia e Venereologia. 2015;73(4):479-483.

4. Mejia PA, Restrepo R, Toro AM, et al. Leishmaniasis mucocutánea verrucosa: una manifestación inusual. Revista de la Asociación Colombiana de Dermatología y Cirugía Dermatológica. 2008;16(2):9799.

5. Rangel EF, Azevedo ACR, Andrade CA, Souza NA, et al. Studies on sandfly fauna (Diptera: Psychodidae) in a foci of cutaneous leishmaniasis in mesquita, Rio de Janeiro State, Brazil. Mem Inst Oswaldo Cruz, Rio de Janeiro. 1990;85(1):39-45.

6. Marfurt J, Nasereddin A, Niederwieser I, et al. Identification and differentiation of Leishmania species in clinical samples by PCR amplification of the miniexon sequence and subsequent restriction fragment length polymorphism analysis. Journal of Clinical Microbiology. 2003;41(7):3147-3153. 
7. Gutierrez Y, Salinas GH, Palma G, et al. Correlation between histopathology, immune response, clinical presentation, and evolution in Leishmania braziliensis infection. The American Journal of Tropical Medicine and Hygiene. 1991;45(3):281-289.

8. Biddlestone LR, Hepburn NC, McLaren KM, et al. A clinicopathological study of cutaneous leishmaniasis in British troops from Belize. Transactions of the Royal Society of Tropical Medicine and Hygiene. 1994;88(6):672-676.

9. Magalhães AV, Moraes MAP, Raick NA, et al. Histopatologia da leishmaniose tegumentar por Leishmania b. brasiliensis. Padrões histológicos e estudo evolutivo das lesões. Revista do Instituto de Medicina Tropical de São Paulo, São Paulo. 1986;28(4):253-262.

10. You TK, Kim KM, Noh SJ, Bae JS, et al. Expressions of E-cadherin, Cortactin and MMP-9 in pseudoepitheliomatous hyperplasia and squamous cell carcinoma of the head and neck: Their relationships with clinicopathologic factors and prognostic implication. Korean journal of pathology. 2012;46(4)331-340.

11. Akiov AL, Oleg E, Donovan MJ, et al. T helper type 1 cytokines and keratinocyte growth factor play a critical role in pseudoepitheliomatous hyperplasia initiation during cutaneous leishmaniasis. Archives of Dermatological Research. 2007;299(7)315-325.
12. Nayak VN, Ks U, Girish HC, et al. Pseudoepitheliomatous hyperplasia in oral lesions: A Review. Journal of international oral health: $\mathrm{JIOH}$. $2015 ; 7(9) 148$.

13. Villa RT, Hostalácio IFF, Tranquillini G, et al. Hiperplasia pseudoepiteliomatosa: uma reação rara à tatuagem. Med Cutan Iber Lat Am. 2011;39(6):272-274.

14. Tan KB, Tan SH, Aw DCW, et al. Simulators of squamous cell carcinoma of the skin: diagnostic challenges on small biopsies and clinicopathological correlation. Journal of skin cancer. 2013.

15. Swanson PE, Fitzpatrick MM, Ritter JH, et al. Immunohistologic differential diagnosis of basal cell carcinoma, squamous cell carcinoma, and trichoepithelioma in small cutaneous biopsy specimens. Journal of cutaneous pathology. 1998;25(3)153-159.

16. Al-kamel, MAN. Leishmaniasis and Malignancy: A Review and Perspective. Clinical Skin Cancer. 2017;2(1-2):54-58.

17. MORSY, T A. Cutaneous leishmaniasis predisposing to human skin cancer: forty years local and regional studies. Journal of the Egyptian Society of Parasitology. 2013;43(3):629-648. 